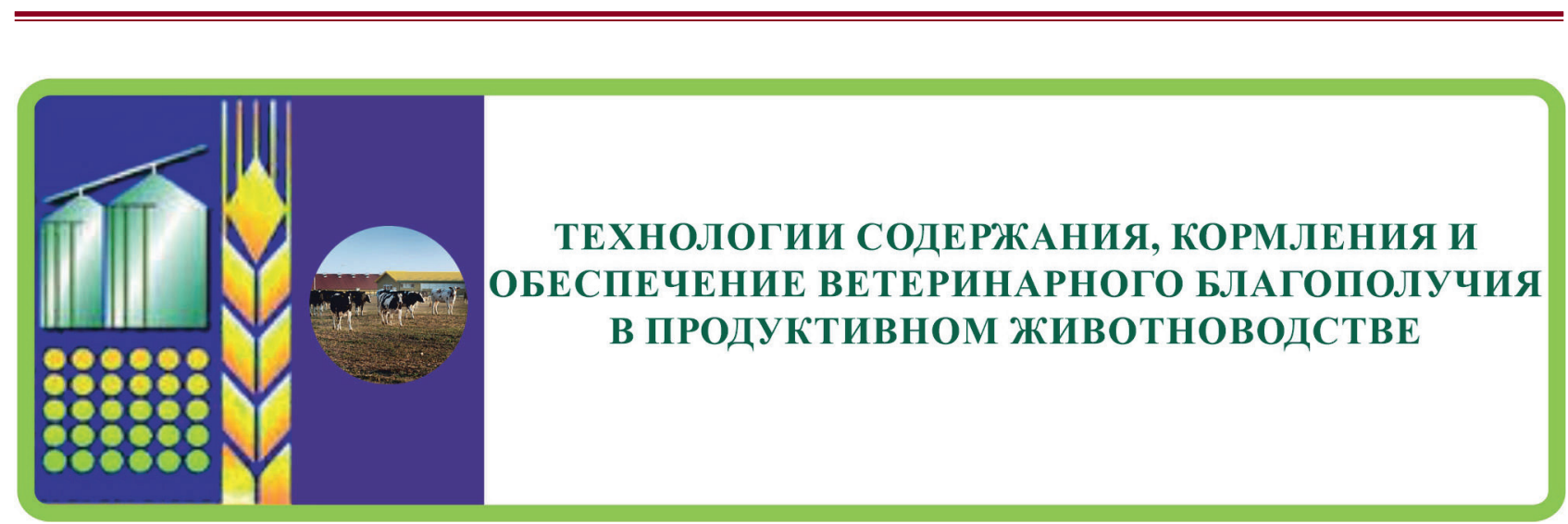

УДК 636.4:575.174:591.4

DOI:10.31677/2072-6724-2021-33-3-80-94

\title{
ГЕТЕРОГЕННОСТЬ ПОПУЛЯЦИЙ И АДАПТАЦИЯ К ТЕХНОЛОГИИ СОДЕРЖАНИЯ ДОМАШНИХ СВИНЕЙ: ПРИЧИНЫ ФОРМИРОВАНИЯ
}

\author{
${ }^{1}$ С.П. Князев, кандидат биологических наук, доцент \\ ${ }^{2}$ C.B. Никитин, кандидат биологических наук \\ ${ }^{1}$ В.И. Ермолаев, доктор биологических наук \\ ${ }^{1}$ Новосибирский государственный аграрный университет \\ ${ }^{2}$ Институт ичитологии и генетики СО РАН \\ E-mail: knyser@rambler.ru
}

Ключевые слова: домашние свиньи, популяции, гетерогенность, внутрипородная дифференциация, стандартизирующий отбор, адаптация к технологии содержания.

Реферат. Проведён анализ результатов исследований популяций домашних свиней за 25-летний период, что позволило рассмотреть ряд положений о роли естественных процессов и стандартизирующего отбора при адаптации популяций к технологическим условиям. Показано, что формирование межпопулячионных различий является результатом естественных генетико-стохастических процессов, а внутрипопуляционные различия (между линиями и семействами) обусловлены соответственно полиморфизмом генов Ү-хромосомы и митохондриальной ДНК. Полиморфизм генетических маркеров в популяииях домашних свиней является следствием проводимых человеком скрещиваний при формировании современных пород, но сам набор этих маркеров в каждой породе и популяции изначально случаен. Ассочиаџии генетических маркеров в популяциях оказываются результатом независимых проиессов: естественного догаметного отбора хромосом (на стадии гаметогенеза) и искусственного стандартизирующего отбора. Обнаружено, что частота носителей эндогенных ретровирусов PERV в популяциях свиней связана с условиями внешней среды и отражает уровень благополучия популяции. Построена модель связи гомо- и гетерозиготности популяции свиней с вариацией количественных признаков: развитие гетерозигот может быть нестабильным ввиду наличия у них большего числа степеней свободы при реализачии фенотипа. Гены локусов, которые формируют генотипы, соответствующче определению: «генотипу соответствует множество фенотипов, а фенотипу соответствует множество генотипов», названы авторами «генами адаптачии». Вклад стандартизирующего отбора растёт по мере прогресса породообразования, при этом увеличивается гетерогенность. Доместикачионная часть генома Sus scrofa coстоит из консервативной гомозиготной базовой части и зависимой от условий среды гетерозиготной «надстройки». Поэтому в популячиях современных «коммерческих» пород свиней сформированы, на первый взгляд, парадоксальные генетические компаунды, обеспечивающие необходимый адаптащионный потенщиал. Так, в локусах, регулируюших онто- 
генез, в гетерозиготном состоянии сохраняются рецессивные аллели, детерминирующие низкую скорость роста, - из-за повышенной приспособленности гетерозигот, у которых аллели, увеличивающие эмбриональную смертность, являются оптимизаторами желательной величины помёта.

Стандартизирующий отбор, в сущности, такой же фактор окружающей среды, как и все прочие, контролируемые и не контролируемые человеком. Сочетание особенностей, присущее популяциям продуктивных животных, имеет генетическую структуру, принципиально отличную от панмиктической модели, опирающейся на постулат о случайности скрещиваний. Генетическая структура популяций продуктивных животных основана на неслучайности скрещиваний, на взаимодействиях стандартизирующего отбора с адаптацией к технологическим условиям и на подразделённости на линии и семейства, что кардинально отличает их от популяций диких и лабораторных животных. Следует принять как данность, что современные породы являются «искусственными» образованиями, в которых фено- и генофонд контролирует, в первую очередь, человек, а не природные и случайные факторы или процессы [1]. Популяции домашних животных являются совокупностями особей доместицированной формы какого-либо вида, фенотипическая однородность и генотипическая структура которых формируются стандартизирующим отбором [2] и адаптацией к условиям внешней среды [3]. В рамках данной концепции популяции - это группы относительно родственных особей, фенотипически сходных, но генотипически разнообразных [1].

В современном свиноводстве животные на промышленных комплексах большую часть своей жизни проводят в специально оборудованных помещениях, поэтому адаптация к технологии содержания имеет большее значение, чем к природно-климатическому окружению, влиявшему на свиней в экстенсивном прошлом. Генетическая структура популяций домашних свиней представляет собой взаимодействие и компромисс между требованиями стандартизирующего отбора и адаптацией к конкретным технологическим условиям. Это означает, что в разных технологических условиях одни и те же стандартные значения признаков формируют адаптивные генотипы, наиболее соответствующие этим условиям. Следовательно, при различной технологии содержания популяции одной породы при внешнем фенотипическом сходстве будут различаться генотипически. Таким образом, наряду со стандартизирующим отбором, разнообразие технологий содержания эффективно способствует формированию межгруппового генетического разнообразия и, соответственно, более быстрой генетической (но не фенотипической) дифференциации популяций, чем это могут обеспечить случайные генетико-стохастические процессы. Нормальное существование и сохранение комплекса отличительных признаков для современных пород возможно только в условиях стандартизирующего отбора. В сущности, эти породы можно рассматривать как совокупности отобранных человеком генотипов, сходных по проявлению ряда признаков и адаптированных к определённым технологическим условиям. Изменение генофонда таких пород оказывается следствием изменения технологии их содержания и (или) векторов стандартизирующего отбора. В совокупности эти процессы обеспечивают резерв изменчивости, способный при селекции обеспечить процветание и прогресс породы.

Целью настоящей статьи является обобщение результатов проведённых авторами многолетних исследований и выявление основных компонент, участвующих в формирования внутри- и межгрупповой гетерогенности домашних свиней.

Для анализа использованы результаты многолетних исследований нескольких тысяч свиней разных пород и подвидов диких кабанов, материалы которых опубликованы авторами в статьях и монографиях с 1994 по 2020 г. [1-10]. На основании этих результатов были проведены обобщения и предложены гипотезы о механизмах процессов, происходящих в популяциях сельскохозяйственных животных. 
Кроме того, для изучения на популяциях коммерческих продуктивных пород выявленного среди лабораторных мини-свиней эффекта влияния Ү-хромосомы на скорость пренатального роста [11] были исследованы происхождение и показатели роста свиней кемеровской породы [12]. Для этого изучены материалы зоотехнического учёта 384 хряков и 1230 свиноматок племенного завода «Юргинский» (Кемеровская область). Анализ родословных позволил среди них выделить 240 хряков как носителей Y-хромосом беркширских хряков-родоначальников кемеровской породы [13]. Поэтому мы их объединили в группу $\mathrm{Y}_{\text {в }}$ Остальные 144 хряка, как оказалось, по прямой мужской линии родословных происходили от родоначальников крупной белой, сибирской северной и сибирской черно-пёстрой пород. Эта группа хряков обозначена как $\mathrm{Y}_{\mathrm{L}}$. Среди исследованных кемеровских свиноматок носителями митохондриальной ДНК беркширской породы оказались 170 особей, объединенные в группу m-В. Остальные 1060 свиноматок происходят от помесей местных сибирских свиней с крупной белой породой - их определили в группу m-A. Это структурирование исследованных кемеровских свиней позволило провести анализ их биологических и хозяйственно важных особенностей в зависимости от наличия в их геноме хромосом, унаследованных от определенных пород-родоначальников. Статистическую обработку данных проводили общепринятыми методами [14].

Проводившиеся нами независимые исследования показывают, что причины различий между породами и внутрипородными популяциями (межпопуляционные) и между линиями и семействами (внутрипопуляционные) различны. Различие популяций по встречаемости и частотам различных генетических маркеров является результатом генетико-стохастических процессов [6]. Различия между линиями хряков и между семействами свиноматок обусловлены генами Ү-хромосомы у хряков и митохондриальной ДНК (m-ДНК) у свиноматок. Таким образом, генеалогическое разнообразие хряков и свиноматок отражает полиморфизм этих генов, а различия между генеалогическими группами являются следствием данного полиморфизма. Первое подтверждение существования полиморфизма генов Ү-хромосомы было сделано нами в 2007 г. на представительных выборках свиней разных пород [15]. Значительно позднее авторы в содружестве с коллективом коллег [11] в селекционной группе мини-свиней ИЦиГ СО РАН выявили достоверное различие по массе поросят при рождении между потомками хряков-носителей азиатского и европейского вариантов Ү-хромосомы. Анализ, результаты которого излагаются в настоящей статье, является продолжением этого исследования.

В табл. 1 приведены статистические итоги определения влияния Ү-хромосом и $\mathrm{m}-Д Н К ~$ разного происхождения на воспроизводительные признаки свиней кемеровской породы.

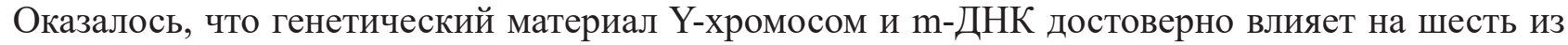
семи исследованных признаков (недостоверными были только различия по средней массе потомка на 21-й день от рождения; для свиноматок недостоверны также различия по сохранности их потомков на 21-й и 60-й день).

Интересно, что в кемеровской породе носители Ү-хромосом предковой для них беркширской породы по всем показателям, включая и среднюю массу потомка на 21-й день, превышали хряков с альтернативной Y-хромосомой, полученной ими от родоначальников других пород, использованных при выведении кемеровских свиней. У свиноматок в племзаводе «Юргинский» картина оказалась противоположной. Все показатели, кроме средней массы потомка на 21-й день, у носительниц беркширской т-ДНК были ниже, чем у носительниц т-ДНК другого происхождения (от крупной белой и от сибирских свиней). 


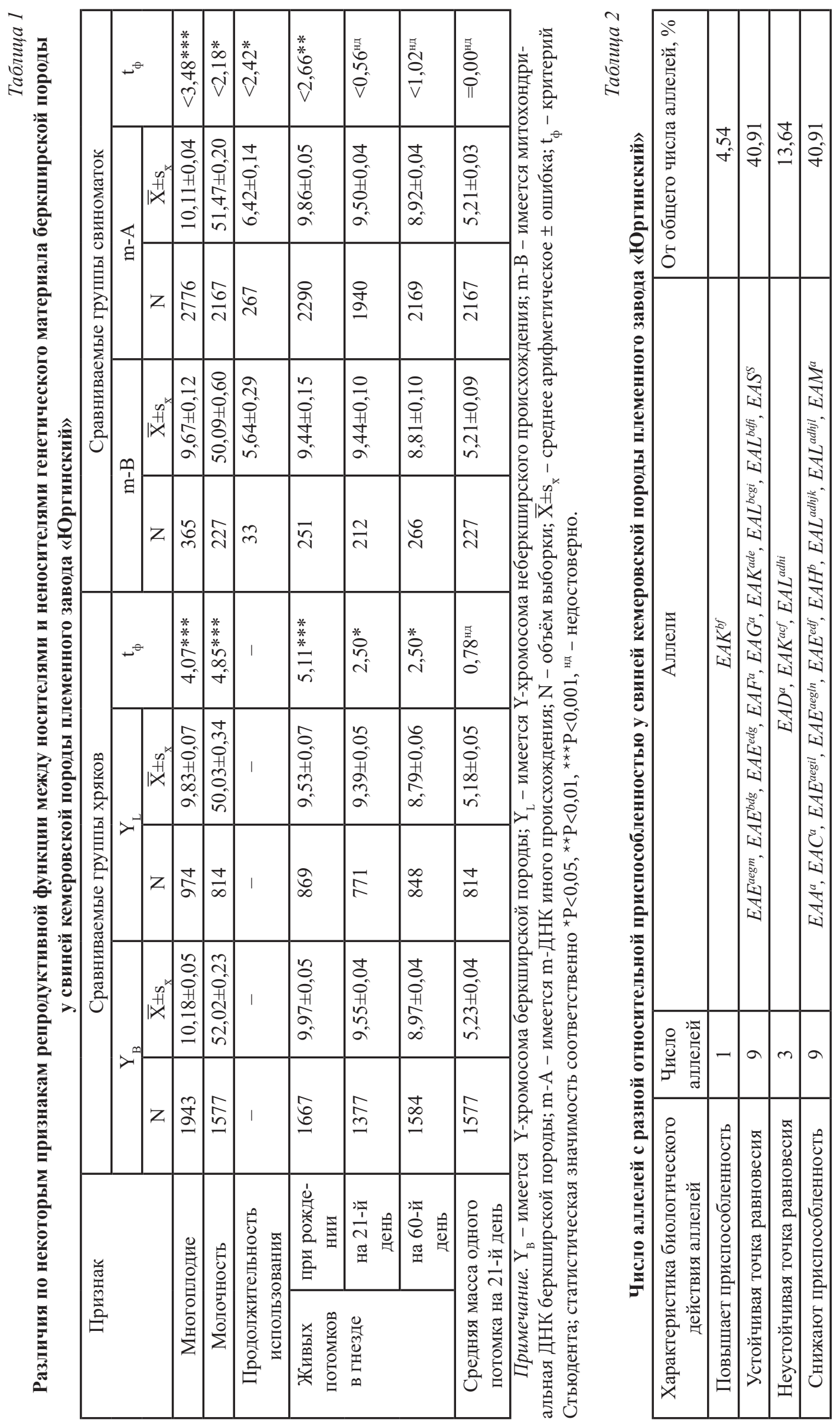


В целом результаты нашего исследования показывают, что полиморфизм по генетическому материалу, заключенному в Ү-хромосомы, передающиеся по «отцовской» стороне родословных, и в митохондриальную т-ДНК, передаваемую по «женской» линии, действительно существует и влияет на ряд селекционно-значимых признаков у кемеровских свиней. Это обстоятельство особенно важно, поскольку среди селекционеров всё ещё распространено мнение, что внутри одного стада (как и в пределах породы), ввиду постоянного «перемешивания» аллелофонда, линии и семейства являются «пустой» формальностью и не обладают передаваемым в ряде поколений генетическим своеобразием. Наши исследования показывают, что линии и семейства отнюдь не формальности и отнюдь не «пустые», и реципрокные генеалогические ряды поколений получают, сохраняют и передают от предков к потомкам адаптационные комплексы генов, локализованных конкретно в мужских хромосомах и в митохондриальных молекулах ДНК.

Полиморфизм и гетерозиготность генетических маркеров у различных пород домашних свиней и подвидов дикого кабана неоднократно описаны в литературе [16-21]. Гетерозиготность является интегральным показателем генетического разнообразия популяции, отражающим результаты неслучайности скрещиваний, отбора, миграций, дрейфа генов, мутационного процесса и других факторов $[22,23]$. Считается также, что гетерозиготность как таковая может служить адаптивным механизмом, обеспечивая приспособленность популяции в варьирующих условиях внешней среды $[24,25]$. Полиморфизм генетических маркеров и соответственно гетерозиготность по ним у современных пород свиней можно рассматривать как остаточное явление $[7,21,26]$, обусловленное скрещиванием различных диких и домашних форм Sus scrofa $[27,28]$.

Поэтому можно достаточно уверенно предположить, что набор аллелей различных локусов генетических маркеров в каждой породе и популяции этого вида большей частью случаен. Очевидно, что на начальной стадии формирования породы, когда требуется быстро получить однородную группу высокопродуктивных животных, существенное значение имеют неспецифические эффекты.

Их следствием, очевидно, и явилось, в частности, выявленное нами значительное число аллелей систем групп крови с устойчивой точкой равновесия у свиней кемеровской породы племзавода «Юргинский» [26]. Всего в генофонде этой популяции, «корневой» для всей кемеровской породы свиней, мы идентифицировали 22 аллеля в 11 генетических системах групп крови $E A A, E A C, E A D, E A E, E A F, E A G, E A H, E A K, E A L, E A M, E A S$ (табл. 2). Из этих 22 аллелей повышал приспособленность только 1 (4,54 \% от всех выявленных аллелей), тогда как понижали её 9 аллелей (40,91\%) и находились в состоянии равновесия остальные 12 аллелей (54,55 \%). Таким образом, в генофонде популяции 1 аллель находился на стадии роста частоты, 9 - на стадии элиминации, 3 - в состоянии неустойчивого равновесия (приспособленность гетерозигот ниже приспособленности гомозигот) и 9 аллелей - в состоянии устойчивого равновесия (приспособленность гетерозигот выше приспособленности гомозигот).

При изучении популяций домашних и диких свиней неоднократно встречались ассоциации генетических маркеров, локализованных на разных хромосомах. Первоначально предполагалось, что это следствие искусственного и естественного отбора по сцепленным локусам селекционно-ценных признаков [5]. Позднее, в процессе углубленного анализа, была выдвинута гипотеза [1], постулирующая конкуренцию гомологичных хромосом в оогенезе (догаметный отбор), которая ведёт к образованию хромосомных комплексов, способных передаваться от матери потомкам как единое целое длительное время. Вполне вероятно, некоторые из положительных ассоциаций маркеров негомологичных хромосом у домашних свиней и комплексы аллотипов несцепленных локусов у диких кабанов $[5,21]$ могут маркировать фрагменты хромосомных блоков, формируемых догаметным отбором. 
В межгрупповую гетерогенность свиней, несомненно, вносят свой вклад и эндогенные ретровирусы, в частности, $P E R V[29,30]$. Частоты носителей PERV зависят от условий существования животных: чем более гармонично сочетаются условия внешней среды с генотипом животных, тем ниже частота носителей $P E R V$ и насыщенность генома этими ретровирусами [30-32], которые наиболее редки у обитающих в естественных условиях диких кабанов и в породах современной европейской селекции, соблюдающей стандартные технологии свиноводства. Напротив, наибольшая встречаемость носителей $P E R V$ и наибольшее число повторностей ретровируса обнаружены нами в геноме мини-свиней ИЦиГ СО РАН, селекция которых проходила в весьма суровых условиях [33].

Весьма интересным представляется вопрос о том, обусловлены ли эти различия действием условий среды, способствующей репликации и распространению бесполезного ретровируса, или это естественный атрибут процесса адаптации к условиям, в которых ретровирус играет полезную роль. Ответ на этот вопрос, мы надеемся, будет найден со временем, а пока частота носителей $P E R V$ в популяции может служить своеобразным индикатором её соответствия условиям среды обитания [34].

Нами была разработана и экспериментально подтверждена модель влияния гетерозиготности по генам, контролирующим количественные признаки свиней, на их вариацию в фенотипах. Согласно модели [35], дисперсия признака у гомозигот является результатом взаимодействия данного аллеля с генетическим фоном популяции, а дисперсия признака у гетерозигот представляет сумму взаимодействий двух аллелей с этим генетическим фоном.

Развивая положения модели, в настоящей статье это можно представить как

$$
\left\{\begin{array} { l } 
{ A _ { 1 } A _ { 2 } } \\
{ A _ { 2 } A _ { 2 } } \\
{ A _ { 1 } A _ { 2 } }
\end{array} \rightarrow \left\{\begin{array}{l}
\sigma_{g m 1}^{2}=\sigma_{A 2}^{2} \\
\sigma_{g m 2}^{2}=\sigma_{A 2}^{2} \\
\sigma_{g t}^{2}=L\left(\sigma_{A 1}^{2}+\sigma_{A 2}^{2}\right),
\end{array}\right.\right.
$$

где $A_{1}$ и $A_{2}$ - аллели гена, контролирующего признак; $\sigma_{g m 1}^{2}, \sigma_{g m 2}^{2}, \sigma_{g t}^{2}-$ дисперсии признака в генотипических классах; $\sigma_{A 1}^{2}, \sigma_{A 2}^{2}-$ дисперсии признака, обусловленные соответственно аллелями $A_{1}$ и $A_{2} ; 0<L<1$ - коэффициент сокращения дисперсии у гетерозигот, обусловленный совпадением действия аллелей, её составляющих.

Приняв равенство дисперсий признака у гомозигот $\left(\sigma_{g m 1}^{2}=\sigma_{g m 2}^{2}\right)$, упрощаем систему уравнений до

$$
\left\{\begin{array} { l } 
{ \text { гомозиготы } } \\
{ \text { гетерозиготы } }
\end{array} \rightarrow \left\{\begin{array}{l}
\sigma_{g m}^{2}=\sigma_{A}^{2} \\
\sigma_{g t}^{2}=2 L \sigma_{A}^{2}
\end{array}\right.\right.
$$

где $\sigma_{A}^{2}$ - дисперсия, обусловленная взаимодействием отдельного аллеля с генетическим фоном популяции.

Модель постулирует некоторые зависимости, обусловленные отбором по жизнеспособности и стандартизацией: особи, адаптированные к условиям существования популяции, обладают оптимальной для них скоростью роста. Низкая приспособленность и пониженная жизнеспособность, напротив, сопровождают снижение скорости роста. Согласно нашей модели [35], гетерозиготы по сравнению с гомозиготами отличаются повышенной изменчивостью скорости роста. Следовательно, в классе гетерозигот повышены доли как медленнорастущих, так и быстрорастущих особей. В условиях отбора - естественного и искусственного стандартизирующего - особи с низкой скоростью роста имеют и низкую приспособленность. Поэтому в результате отбора по скорости роста распределение гетерозигот в популяции будет иметь положительную асимметрию: среднее значение признака увеличивается, а между гетерозиготностью и признаками скорости роста формируются положительные корреляции. Причём с возрастом эти явления будут усиливаться. 
Данную модель мы применили также для описания различий между гомо- и гетерозиготами по стабильности развития [1]. Развивая это положение, представим, что в гене $A$ существуют три генотипа диаллельного локуса: $A_{1} A_{1}, A_{2} A_{2}$ и $A_{1} A_{2}$, которые обозначим соответственно как $G_{1}, G_{2}$ и $G_{12}$. Эти генотипы могут быть реализованы в виде одного из трёх фенотипов: $P_{1}$, $P_{2}$ и $P_{12}$. Соответствие между генотипами и фенотипами следующее:

$$
G_{1} \rightarrow P_{1}, G_{2} \rightarrow P_{2} \text { и } G_{12} \rightarrow\left\{\begin{array}{l}
P_{1} \\
P_{2} \\
P_{12}
\end{array}\right.
$$

То есть, каждый из гомозиготных генотипов может быть реализован только в виде одного фенотипа (диапазона значений), тогда как гетерозиготный генотип способен реализоваться в виде любого из трёх возможных фенотипов. Таким образом, гомозиготы имеют детерминированный путь развития, тогда как свойственная гетерозиготам возможность «выбора» одного из трёх путей фенотипической реализации может стать основой для нестабильности развития. Представим путь фенотипической реализации гетерозиготного генотипа как последовательность точек, в каждой из которых происходит выбор фенотипа. Для гетерозигот число таких точек будет связано с уровнем стабильности развития. Гетерозигота с одной точкой выбора после определения реализуемого фенотипа будет стабильно развиваться по пути его реализации. Если же число точек выбора больше единицы и все они равноценны, то в разных точках векторы реализации могут быть направлены на разные фенотипы. Следовательно, до момента окончательного формирования признака особь будет неравномерно развиваться в направлении разных фенотипов, т.е. её развитие будет нестабильным. Путь фенотипической реализации особи со стабильным развитием можно представить как прямую линию, соединяющую генотип с фенотипом. Путь фенотипической реализации гетерозиготы с нестабильным развитием представляет собой ломаную линию с разной длиной составляющих её отрезков, векторы которых направлены на разные фенотипы. Так как направление развития особи в точках выбора изменяется, то чем больше этих точек находится на линии, соединяющей генотип с фенотипом, тем более нестабильным будет развитие особи. В целом стабильный путь развития оказывается более коротким и энергетически менее затратным - изменение векторов развития не только удлиняет путь фенотипической реализации, но и требует дополнительных затрат для ликвидации ненужных последствий движения по предыдущему вектору. Соответственно, особи с нестабильным развитием по селекционно-ценным показателям в среднем должны уступать особям со стабильным развитием. Однако даже при нестабильном развитии гетерозиготы всё равно будут иметь преимущество перед гомозиготами, так как, имея больше степеней свободы, будут лучше приспособлены к условиям среды, и в тех случаях, когда гомозигота погибнет или отстанет в росте и будет выбракована, гетерозигота имеет реальные шансы уцелеть.

Зависимость современных пород сельскохозяйственных животных от проводимых человеком селекционных и технологических мероприятий приводит к тому, что при ослаблении давления (или исчезновении) этих факторов заводская порода в течение относительно небольшого числа поколений претерпевает изменения, обратные прогрессивной эволюции, и возвращается к состоянию одной из архаичных форм - об этом убедительно сказано еще С.Н. Боголюбским в 1959 г. [36].

Высокая скорость деструктивного преобразования фенотипического облика созданной породы в случае прекращения целенаправленной селекции позволяет выдвинуть три взаимодополняющих положения:

1. Контролируемая человеком часть генофонда доместицированной популяции незначительна. 
2. В контролируемую человеком часть генофонда входят главным образом локусы в гетерозиготном состоянии.

3. Рецессивные аллели, сохраняющиеся у гетерозигот, имеют адаптивные преимущества перед поддерживаемыми стандартизирующим отбором доминантными аллелями.

Эти положения обусловливают актуальность вопросов фенотипической реализации генотипа в виде конкретного значения детерминируемого им признака. Такой процесс реализации признака можно представить, как последовательность событий на пути от генотипа к фенотипу, которые могут быть как случайными, так и зависимыми от внешних условий.

В рамках этой концепции весьма интересным признаком свиней является масса новорождённого поросёнка, поскольку её рост определяют как случайные факторы, так и обеспечиваемые технологиями условия среды развития особи [37, 38]. Масса новорождённого поросёнка относится к классу признаков, главная особенность которых состоит в том, что любой из формирующих его генотипов может быть реализован в виде любого из возможных значений - фенотипов. В свою очередь, любому из фенотипов будет соответствовать множество генотипов, т.е. для фенотипической реализации любого из генотипов доступным является весь диапазон биологически возможных значений признака. Как следствие, таким признакам присуща высокая чувствительность к внешним воздействиям и способность к адекватному и сходному для разных генотипов ответу. У этого класса признаков процесс фенотипической реализации генотипа имеет максимально возможное число степеней свободы; размах значений признака ограничен только условиями среды и биологическими возможностями вида. Изменение условий среды или векторов отбора приводит к изменению диапазона значений признака, который одинаков для всех генотипов, а реализованные фенотипы распределяются в диапазоне возможных значений случайным образом [10]. Следовательно, при одинаковом воздействии внешних условий разные генотипы по локусам, контролирующим признак, дают сходный фенотипический ответ на это воздействие. Примером такого воздействия может быть описанный нами у свиней «материнский эффект» $[39,40]$.

Таким образом, гены, отвечающие за формирование подобных признаков, можно рассматривать как гены приспособленности, обеспечивающие адаптацию организма к нестабильным условиям внешней среды, т.е. отвечающие за формирование диапазона нормы реакции организма на эти условия. Именно эти гены, чьи аллели формируют генотипы, соответствующие определению: «генотипу соответствует множество фенотипов (значений признака), а фенотипу соответствует множество генотипов», и являются «генами адаптации». Они составляют ту часть генофонда популяции, которая обеспечивает её устойчивость к изменениям окружающей среды и к смене векторов отбора, поскольку реализуемые ими фенотипы изменяются при изменении указанных параметров. Однако это означает только смену диапазона вариации, а не пропорциональное изменение реализуемых конкретными генотипами значений признака. Распределение реализованных фенотипов внутри диапазонов возможных значений - как прежнего, так и нового - будет случайным. Поэтому корреляция между фенотипами, реализованными одним и тем же генотипом в разных условиях, будет отсутствовать.

Стандартизирующий отбор не только формирует фенотипическое однообразие и генетическую гетерогенность породы. Он обеспечивает её прогресс. Стандартизация животных является отбором по фенотипу - для воспроизводства отбирают особей, у которых значения селекционируемых признаков лежат в диапазонах, определяемых стандартами породы. Так как эти значения могут реализовывать разные генотипы - как гомо-, так и гетерозиготные, - стандартизирующий отбор формирует совокупности животных, сходных внешне, но гетерогенных генотипически. 
Вклад стандартизирующего отбора растёт пропорционально доместикационному прогрессу, одновременно увеличивая гетерогенность домашней формы. У свиней вида Sus scrofa L. этот процесс описывает следующая последовательность:

\section{дикий кабан $\rightarrow$ примитивная домашняя свинья $\rightarrow$ современная порода}

В этой последовательности стандартизирующий отбор у дикого кабана отсутствует, у примитивной домашней свиньи он меньше вклада климатических и географических факторов (у примитивных полудиких пород он может практически отсутствовать), у современных заводских пород вклад стандартизирующего отбора значительно больше вклада климатических и географических факторов. Аналогично растёт и генотипическое разнообразие, что показано при изучении полиморфизма систем групп крови в популяциях домашних и диких свиней. Минимальное аллельное разнообразие наблюдалось в популяциях диких кабанов, затем следуют аборигенные породы, а максимальное аллельное разнообразие присутствует у современных европейских пород [16].

Стандартизирующий отбор, выравнивая породу фенотипически, оптимизирует внутригрупповой генетический полиморфизм. Результатом этого процесса является то, что породы одного направления продуктивности, так же как и локальности одной породы, содержащиеся в разных технологических условиях, при внешнем фенотипическом сходстве могут различаться генотипически. Кстати, это может быть причиной гетерозиса при скрещивании животных разных пород одного направления продуктивности или при скрещивании животных одной породы из разных внутрипородных популяций.

Построим модель данного явления. Будем исходить из того, что у домашних свиней за крупные размеры отвечают доминантные, а за мелкие - рецессивные аллели [40]. Предположим, что родительские группы свиней имеют генотипы $A_{1} / A_{1} a_{2} / a_{2} \ldots a_{n} / a_{n}$ и $a_{1} / a_{1} a_{2} / a_{2} \ldots A_{n} / a_{n}$. Помеси первого поколения будут иметь генотип $A_{1} / a_{1} a_{2} / a_{2} \ldots A_{n} / a_{n}$, т.е. вместо одного локуса с доминантным аллелем «крупных размеров» у них будет два таких локуса, и, естественно, они окажутся крупнее родителей [1], демонстрируя гетерозис как превышение потомков по размерам над обеими родительскими формами.

Наши исследования показали, что геном домашних свиней состоит из двух связанных с доместикацией частей - базовой и «надстройки» [41]. Первичной является базовая часть генома, которая сформировалась несколько тысяч лет тому назад как ответ на изменение условий существования при одомашнивании. Она сохранилась в явном виде у примитивных пород свиней, для которых характерна низкая продуктивность, сравнительно мало способная к повышению при улучшении условий кормления и содержания. «Надстройка» сформирована у селекционно «продвинутых» современных заводских пород как итог целенаправленного накопления селекционерами в большом ряду поколений домашних свиней генов, обусловливающих существенный прогресс продуктивности при совершенствовании технологических параметров свиноводства. У этих свиней базовая часть генома находится в скрытом, неэкспрессируемом виде, в «тени» надстройки, проявляясь при ухудшении отсутствии условий содержания и селекционных мероприятий. Надо полагать, что подобная устойчивость и консервативность части генома, составляющей его базовую доместикационную часть, может быть обусловлена гомозиготностью локусов, её контролирующих. «Надстройка» вторична, она появилась уже в новое время при создании современных заводских пород, для формирования которых было необходимо обильное, сбалансированное и полноценное кормление животных и соблюдение технологий содержания, выращивания, воспроизводства, а для сохранения комплекса хозяйственно важных породных признаков - непрерывный стандартизирующий отбор. В итоге заводские породы оказались полностью зависимы от этих параметров. В ненадлежащих условиях содержания «надстройка» переходит в состояние нереализованной возможности, а при отсутствии 
стандартизирующего отбора разрушается, оставляя после себя только базовую часть доместикационного генома. Последнее - разрушение при отсутствии стандартизирующего отбора указывает на высокую гетерозиготность «надстройки».

Следует заметить, что в условиях обязательного отбора по скорости роста носители аллелей, снижающих приспособленность, увеличивая раннюю эмбриональную смертность и, соответственно, уменьшая величину помёта, снижают конкуренцию между однопомётниками за материнский ресурс в подсосный период онтогенеза. Поскольку поросята из относительно немногоплодных помётов, как правило, растут быстрее, это и в дальнейшие периоды выращивания повышает их шансы на прохождение отбора в репродуктивное ядро.

Таким образом, снижающие эмбриональную жизнеспособность аллели параллельно могут повышать приспособленность гетерозиготных носителей, что и может быть причиной указанного в табл. 2 присутствия среди 22 аллелей у свиней племенного ядра кемеровской породы 9 аллелей, снижающих приспособленность [26]. Но проводимый человеком отбор требует соответствия породному стандарту не только самой особи, но и её потомства, поэтому подобные эффекты теоретически должны носить временный характер. Однако элиминация рецессивных аллелей, в том числе летальных и сублетальных - процесс длительный, учитывая их наличие в скрытом виде у гетерозигот, особенно если они повышают их конкурентоспособность. Продолжая оставаться в популяции в виде генетического груза, они являются своеобразным резервом на случаи ухудшения условий содержания, когда высокое многоплодие становится излишне высоким. В таких случаях аллели, снижающие размер помёта (многоплодие), позволяют относительно быстро снизить его значение до уровня, оптимального в данных условиях. Носители таких аллелей гетерозиготны, поэтому при наступлении благоприятных изменений, уровень воспроизводства популяции достаточно быстро может восстановиться благодаря генотипическому расщеплению. Так как условия среды постоянно варьируют, будет варьировать и оптимальный для популяции уровень многоплодия, поддерживая в ней эти аллели, которые, возможно, являются атрибутом популяций многоплодных животных, будучи своего рода генами адаптации «быстрого реагирования» [26].

В свете рассмотренных вопросов адаптации и отбора нам представляется актуальным рассмотреть взаимоотношения этих двух явлений как процессов. Прежде всего, следует отметить, что отбор (и естественный, и искусственный) воздействует непосредственно не на генотипы или фенотипы, а на результаты взаимодействия генотипа со средой как процесса реализации генотипа в фенотип в условиях окружающей среды, т.е. процесса адаптации организма к этим условиям.

С эволюционной точки зрения, наиболее адаптированными к условиям окружающей среды следует считать особей, производящих более многочисленное, более жизнеспособное и более плодовитое потомство. В такой интерпретации адаптационного процесса отбор можно рассматривать как его завершающий этап: ведь если особь не оставила после себя плодовитых потомков, то её собственная способность к адаптации не имеет никакого эволюционного значения. Более того, когда высокие адаптационные свойства особей сочетаются с их репродуктивной несостоятельностью, их вклад в общую приспособленность популяции будет отрицательным, так как в борьбе за жизненно необходимые ресурсы они являются конкурентами репродуктивно успешных особей.

Применительно к сельскохозяйственным животным, завершающим в каждом поколении этапом адаптации является стандартизирующий отбор. Несоответствие подвергаемой отбору особи комплексу стандартных селекционных требований означает для неё невозможность попадания в воспроизводящий состав, т.е. полностью обесценивает её индивидуальную приспособленность к условиям окружающей среды.

Проведенные исследования позволяют сделать следующие выводы. 
1. Стандартизирующий отбор параллельно с увеличением фенотипического единообразия увеличивает генотипическое разнообразие породы, создавая основу для её дальнейшего прогресса.

2. Разработанная модель показывает, что развитие гетерозигот может быть относительно нестабильным ввиду наличия большего числа степеней свободы при реализации в фенотип по сравнению с гомозиготами. Однако именно эта нестабильность развития придаёт гетерозиготам большую устойчивость в нестабильных, меняющихся условиях внешней среды.

3. Внутрипопуляционные различия между линиями и семействами одной и той же породы по селекционно значимым признакам могут быть следствием полиморфизма генов, локализованных в Y-хромосомах (общих для линии) и в митохондриальной ДНК (передаваемой в поколениях одного семейства).

4. Локусы, аллели которых формируют генотипы, соответствующие определению: «генотипу соответствует множество фенотипов, а фенотипу соответствует множество генотипов», являются «генами адаптации».

5. Частота носителей эндогенных ретровирусов PERV может быть индикатором благополучия популяции.

6. В популяциях продуктивных пород свиней присутствуют во многих локусах в скрытом виде рецессивные аллели, детерминирующие низкую скорость роста, которые повышают приспособленность гетерозигот. Аллели, увеличивающие раннюю эмбриональную смертность, также могут повышать приспособленность гетерозигот, а у свиней как многоплодных животных выполняют функцию оптимизатора величины помёта. Таким образом, эти аллели не являются генетически грузом, а несут вполне определённые полезные функции для прогресса породы.

7. Положительные ассоциации генетических маркеров в популяциях домашних свиней могут быть результатом догаметного отбора хромосом.

8. Доместикационная часть генома домашней свиньи состоит из устойчивой гомозиготной базовой части и зависимой от условий среды гетерозиготной «надстройки».

Работа поддержана бюджетным проектом № 0259-2021-0015.

\section{БИБЛИОГРАФИЧЕСКИЙ СПИСОК}

1. Никитин С.В., Князев С.П. Отбор и адаптация в популяциях домашних свиней: монография. - Saarbrucken: Lambert Academy Publishing (LAP), 2015. - 221 c.

2. Князев С.П., Никитин С.В. Стандартизирующий отбор и его последствия для генетической структуры популяции // Генетика. - 2011. - Т. 47, № 1. - С. 103-114.

3. Князев С.П., Никитин С.В. Изменение векторов отбора по массе поросят при рождении в процессе формирования популяции в новых условиях среды // Сельскохозяйственная биология. - 2014. - № 6. - С. 86-95.

4. Никитин C.B., Ворожейкин А.C. Особенности наследования серых пятен у домашних свиней // Генетика. - 1994. - Т. 30, № 5. - С. 675-680.

5. Ассоциащии генетических маркеров в двух родственных породах свиней / С.П. Князев, С.В. Никитин, И.Г. Горелов, В.И. Ермолаев, Г.В. Орлова, М.А. Савина, К.В. Жучаев, С.В. Папшев, Е.В. Кабаненко // Генетика. - 1999. -Т. 35, № 5. - С. 674-680.

6. Дрейф генов как фактор дифференциации внутрипородных популяций свиней / С.П. Князев, С.В. Никитин, М.А. Савина, В.И. Ермолаев, И.Г. Горелов, О.П. Юдина, Н.В. Данильченко, Н.С. Фадеева // Доклады Российской академии сельскохозяйственных наук. - 2004. - № 2. - С. 35-38. 
7. Князев С.П., Никитин С.В. Моделирование структуры супергенов, контролирующих некоторые полиаллельные системы групп крови свиньи Sus scrofa и лошади Equus caballus // Генетика. - 2007. - Т. 43, № 3. - С. 382-392.

8. Генетические методы в селекции свиней: монография / В.А. Бекенев, В.Н. Дементьев, В.И. Ермолаев, Г.М. Гончаренко, В.С. Деева, С.В. Никитин, С.П. Князев [и др.]; Сиб. НИИ жив-ва Россельхозакадемии. - Новосибирск, 2012. - 116 с.

9. Никитин С.В., Князев С.П., Ермолаев В.И. Вариация массы новорождённой особи у домашних свиней и процесс адаптации // Вавиловский журнал генетики и селекции. - 2014. T. 18, № 2. - С. 263-278.

10. Никитин С.В., Князев С.П., Ермолаев В.И. Роль условий среды пренатального роста плодов в формировании массы новорожденной особи у домашних свиней // Вавиловский журнал генетики и селекции. - 2017.- Т. 21, № 5. - С. 569-575.

11. Y-chromosome effect on prenatal live weight growth of laboratory minipigs / K. Shatokhin, S. Nikitin, S. Knyazev, V. Zaporozhets, S. Paskovskyi // International Scientific and Practical Conference "From inertia to develop: research and innovation support to agriculture". E3S Web Conf., 2020; 176: 01003. DOI:10.1051/e3sconf/202017601003

12. Князев С.П., Швебель Т.И., Никитин С.В. Биологические особенности свиноматок кемеровской породы с разным потенциалом многоплодия // Свиноводство. - 2007. - № 6. - С. 7-9.

13. Овсянников А.И. Выведение кемеровской сальной породы свиней. - Новосибирск: Кн. изд-во, 1951. $-48 \mathrm{c.}$

14. Лакин Г.Ф. Биометрия. - М.: Высшая школа, 1990. - 352 с.

15. Сцепленные с полом эритроцитарные антигены свиньи / С.В. Никитин, С.П. Князев, Г.М. Гончаренко, В.А. Бекенёв // Генетика. - 2007. - Т. 43, № 4. - С. 521-529.

16. Тихонов В.Н. Иммуногенетика и биохимический полиморфизм домашних и диких свиней. - Новосибирск: Наука, 1991. - 304 с.

17. Иммуногенетический анализ структуры популяций свиней кемеровской и скороспелой мясной пород на этапе их интенсивного развития / С.П. Князев, И.Г. Горелов, К.В. Жучаев [и др.] // Сельскохозяйственная биология. - 1996. - № 2. - С. 57-62.

18. Динамика генетической структуры как отражение микроэволюционных процессов в популяциях свиней сибирских пород / К.В. Жучаев, С.П. Князев,Т.В. Шантурова, И.И. Гудилин // Доклады Российской академии сельскохозяйственных наук. - 1997. - № 4. - С. 24-25.

19. Князев С.П., Никитин С.В. Филогенез и таксономические взаимоотношения внутривидовых форм свиней Sus scrofa (Suidae) // Зоологический журнал. - 2004. - Т. 83, вып. 1. С. 105-117.

20. Дифференщииация диких и домашних свиней по аллотипам белков сыворотки крови / С.П. Князев, С.В. Никитин, А.В. Кириченко [и др.] // Сельскохозяйственная биология. - 2005. № 6. - С. 100-105.

21. Разнообразие популяций диких и домашних свиней по комплексу аллотипов сыворотки крови / С.В. Никитин, С.П. Князев, А.Г. Николаев, А.М. Волох [и др.] // Генетика. - 2006. Т. 42, № 3. - С. 403-413.

22. Животовский Л.А. Популяционная биометрия. - М.: Наука. - 1991. - 272 с.

23. Кайданов Л.3. Генетика популяций. - М.: Высшая школа, 1996. - 320 с.

24. Holderegger R., Kamm U., Gugerli F. Adaptive vs. neutral genetic diversity: implications for landscape genetics // Landscape Ecol. - 2006. - Vol. 21 . - P. 797-807. - https://doi.org/10.1007/ s10980-005-5245-9.

25. Whitlock $R$. Relationships between adaptive and neutral genetic diversity and ecological structure and functioning: a meta-analysis // J. Ecol. - 2014. - Vol. 102 (4). - P. 857-872. - https:// doi.org/10.1111/1365-2745.12240. 
26. Динамика гетерозиготности и её связь с приспособленностью в популяции домашних свиней / С.В. Никитин, С.П. Князев, Т.И. Швебель, Г.М. Гончаренко // Генетика. - 2009. - Т. 45, № 10. - С. 1401-1410.

27. Дарвин Ч. Изменения домашних животных и культурных растений // Сочинения. - М.; Л.: Изд-во АН СССР. - 1951. - Т. 4. - 884 с.

28. Vila C., Seddon J., Ellegren H. Genes of domestic mammals augmented by backcrossing with wild ancestors // Trends in Genetics. - 2005. - Vol. 21, N 4. - P. 214-218.

29. Differentiation of wild boar and domestic pig populations based on the frequency of chromosomes carrying endogenous retroviruses / S.V. Nikitin, N.S. Yudin, S.P. Knyazev [et al.] // Natural Science. - 2010. - Vol. 2, N 6. - P. 527-534.

30. Ассоциащии эндогенных ретровирусов разных типов с генетическими маркерами в популяциях домашних и диких свиней / Р.Б. Айтназаров, В.И. Ермолаев, С.В. Никитин, М.А. Савина, В.Ф. Кобзев, С.П. Князев [и др.] // Доклады Россельхозакадемии. - 2006. - № 4. C. $39-43$.

31. Оченка частоты хромосом, содержащих свиные эндогенные ретровирусы, в популяциях домашней свиньи и дикого кабана / С.В. Никитин, Н.С. Юдин, С.П. Князев, Р.Б. Айтназаров [и др.] // Генетика. - 2008. - Т. 44, № 6. - С. 789-797.

32. Насыщенность генома свиньи эндогенными ретровирусами: влияние наследственности и среды / Р.Б. Айтназаров, С.В. Никитин, С.П. Князев, Н.С. Юдин // Инновации и продовольственная безопасность. - 2013. - № 2. - С. 41-49.

33. Распространение свиных эндогенных ретровирусов у разных форм Sus scrofa L. 1758 (Suidae, Mammalia) / Р.Б. Айтназаров, С.В. Никитин, С.П. Князев [и др.] // Сибиский вестник сельскохозяйственной науки. - 2010. - № 9. - С. 49-54.

34. Дифференциация популяций диких и домашних свиней по частоте хромосом, содержащих эндогенные ретровирусы / Н.С. Юдин, Р.Б. Айтназаров, С.П. Князев [и др.] // Информационный вестник ВОГИС. - 2009. - Т. 13, № 4. - С. 741-750.

35. Модель влияния гомо- или гетерозиготности животных на интенсивность их роста / С.В. Никитин, С.П. Князев, Г.В. Орлова [и др.] // Генетика. - 2005. - Т. 41, № 2. - С. 237-245.

36. Боголюбский С.Н. Происхождение и преобразование домашних животных. - М.: Сов. наука, 1959. - 592 с.

37. Князев С.П., Никитин С.В. Изменение векторов отбора по массе поросят при рождении в процессе формирования популяции в новых условиях среды // Сельскохозяйственная биология. - 2014. - № 6. - С. 86-95.

38. Никитин С.В., Князев С.П., Ермолаев В.И. Генетические компоненты и неопределённость фенотипической реализации массы новорождённой особи у домашней свиньи Sus scrofa L. // Генетика. - 2014. - Т. 50, № 1. - С. 69-78.

39. Князев С.П., Никитин С.В., Ермолаев В.И. Генетика крупноплодности свиней: половой диморфизм и генетический контроль массы новорождённых поросят // Вестник НГАУ. 2013. - № 1. - С. 46-57.

40. Никитин С.В., Князев С.П., Шатохин К.С. Миниатюрные свиньи ИЦиГ- модельный объект для изучения формообразовательного процесса // Вавиловский журнал генетики и селекции. - 2014. - Т. 18, № 2. - С. 279-293.

41. Разведение и селекция мини-свиней ИЦиГ СО РАН / С.В. Никитин, С.П. Князев, К.С. Шатохин, В.И. Запорожец, В.И. Ермолаев // Вавиловский журнал генетики и селекции. 2018. - T. 22, № 8. - C. 922-930. - DOI 10.18699/VJ18.434. 


\section{REFERENCES}

1. Nikitin S.V., Knyazev S.P., Otbor $i$ adaptacija v populjacijah domashnih svinej (Selection and adaptation in domestic pig populations), Saarbrucken: Lambert Academy Publishing, 2015, 221 p.

2. Knyazev S.P., Nikitin S.V., Genetika, 2011, vol. 47, No.1, pp. 103-114. (In Russ.)

3. Knyazev S.P., Nikitin S.V., Sel'skohozjajstvennaja biologija, 2014, No. 6, pp. 86-95. (In Russ.)

4. Nikitin S.V., Vorozhejkin A.S., Genetika, 1994, vol. 30, No. 5, pp. 675-680. (In Russ.)

5. Knyazev S.P., Nikitin S.V., Gorelov I.G., Ermolaev V.I., Orlova G.V., Savina M.A., Zhuchaev K.V., Papshev S.V., Kabanenko E.V., Genetika, 1999, vol. 35, No. 5, pp. 674-680. (In Russ.)

6. Knyazev S.P., Nikitin S.V., Savina M.A., Ermolaev V.I., Gorelov I.G., Judina O.P., Danil'chenko N.V., Fadeeva N.S., Doklady Rossijskoj akademii sel'skohozjajstvennyh nauk, 2004, No. 2, pp. 3538. (In Russ.)

7. Knyazev S.P., Nikitin S.V., Genetika, 2007, vol. 43, No. 3, pp. 382-392. (In Russ.)

8. Bekenyov V.A., Dement'ev V.N., Ermolaev V.I., Goncharenko G.M., Deeva V.S., Nikitin S.V., Knyazev S.P., Savina M.A., Orlova G.V., Ajtnazarov R.B., Yudin N.S., Zabolotnaya A.A., Frolova V.I., Geneticheskie metody v selekcii svinej (Genetic methods in pig breeding), Novosibirsk, 2012, $116 \mathrm{p}$.

9. Nikitin S.V., Knyazev S.P., Ermolaev V.I., Vavilovskij zhurnal genetiki i selekcii, 2014, vol. 18, No. 2, pp. 263-278. (In Russ.)

10. Nikitin S.V., Knyazev S.P., Ermolaev V.I., Vavilovskij zhurnal genetiki i selekcii, 2017, vol. 21, No. 5, pp. 569-575. (In Russ.)

11. Shatokhin K., Nikitin S., Knyazev S., Zaporozhets V., Paskovskyi S., International Scientific and Practical Conference "From inertia to develop: research and innovation support to agriculture", E3S Web Conf., 2020; 176: 01003. DOI:10.1051/e3sconf/202017601003

12. Knyazev S.P., Shvebel' T.I., Nikitin S.V., Svinovodstvo, 2007, No. 6, pp. 7-9. (In Russ.)

13. Ovsjannikov A.I. Vyvedenie kemerovskoj sal'noj porody svinej (Breeding of the Kemerovo greasy breed of pigs), Novosibirsk: Knizhnoe izdatel'stvo, 1951, 48 p.

14. Lakin G.F. Biometrija (Biometrics), Moscow: Vysshaja shkola, 1990, 352 p.

15. Nikitin S.V., Knyazev S.P., Goncharenko G.M., Bekenjov V.A., Genetika, 2007, vol. 43, No. 4, pp. 521-529. (In Russ.)

16. Tihonov V.N. Immunogenetika $i$ biohimicheskij polimorfizm domashnih $i$ dikih svinej (Immunogenetics and biochemical polymorphism of domestic and wild pigs), Novosibirsk: Nauka, 1991, 304 p.

17. Knyazev S.P., Gorelov I.G., Zhuchaev K.V., Gart V.V., Bragin A.V., Sel'skohozjajstvennaja biologija, 1996, No. 2, pp. 57-62. (In Russ.)

18. Zhuchaev K.V., Knyazev S.P., Shanturova T.V., Gudilin I.I., Doklady Rossijskoj Aka-demii sel'skohozjajstvennyh nauk, 1997, No. 4, pp. 24-25. (In Russ.)

19. Knyazev S.P., Nikitin S.V., Zoologicheskij zhurnal, 2004, vol. 83, Issue 1, pp. 105-117. (In Russ.)

20. Knyazev S.P., Nikitin S.V., Kirichenko A.V., Nikolaev A.G., Voloh A.M., Savina M.A., Danil'chenko N.V., Ajtnazarov R.B., Ermolaev V.I., Yudina O.P., Sel'skohozjajstvennaja biologija, 2005, No. 6, pp. 100-105. (In Russ.)

21. Nikitin S.V., Knyazev S.P., Nikolaev A.G., Voloh A.M., Kirichenko A.V., Savina M.A., Ermolaev V.I., Yudina O.P., Bekenev V.A., Ajtnazarov R.B. Genetika, 2006, vol. 42, No. 3, pp. 403413. (In Russ.)

22. Zhivotovskij L.A. Populjacionnaja biometrija (Population biometrics), Moscow: Nauka, $1991,272 \mathrm{p}$. 
23. Kajdanov L.Z. Genetika populjacij (Population genetics), Moscow: Vysshaja shkola, 1996, $320 \mathrm{p}$.

24. Holderegger R., Kamm U., Gugerli F., Landscape Ecol, 2006, vol. 21, pp. 797-807, https:// doi.org/10.1007/s10980-005-5245-9.

25. Whitlock R., J. Ecol, 2014, vol. 102 (4), pp. 857-872, https://doi.org/10.1111/1365-2745.12240.

26. Nikitin S.V., Knjazev S.P., Shvebel' T.I., Goncharenko G.M., Genetika, 2009, vol. 45, No.10, pp. 1401-1410. (In Russ.)

27. Darvin Ch. Izmenenija domashnih zhivotnyh i kul'turnyh rastenij (Changes in domestic animals and cultivated plants), Sochinenija, Moscow, Leningrad: Izd-vo AN SSSR, 1951, vol. 4, $884 \mathrm{p}$.

28. Vila C., Seddon J., Ellegren H., Trends in Genetics, 2005, vol. 21, No. 4, P. 214-218.

29. Nikitin S.V., Yudin N.S., Knyazev S.P., Aitnazarov R., Bekenev V.A., Deeva V., Goncharenko G., Kobzev V., Savina M.A., Ermolaev V., Natural Science, 2010, vol. 2, No. 6, P. 527-534. (In Russ.)

30. Ajtnazarov R.B., Ermolaev V.I., Nikitin S.V., Savina M.A., Kobzev V.F., Knyazev S.P., Goncharenko G.M., Bekenev V.A., Yudin N.S., Doklady Rossel'hozakademii, 2006, No. 4, pp. 39-43. (In Russ.)

31. Nikitin S.V., Yudin N.S., Knyazev S.P., Ajtnazarov R.B., Kobzev V.F., Bekenyov V.A., Savina M.A., Ermolaev V.I., Genetika, 2008, vol. 44, No. 6, pp. 789-797. (In Russ.)

32. Ajtnazarov R.B., Yudin N.S., Nikitin S.V., Knyazev S.P., Innovacii i prodovol'stvennaja bezopasnost', 2013, No. 2, pp. 41-49. (In Russ.)

33. Ajtnazarov R.B., Nikitin S.V., Knyazev S.P., Kobzev V.F., Bekenyov V.A., Deeva V.S., Goncharenko G.M., Yudin N.S., Ermolaev V.I., Sib. vestn. s.-h. nauki, 2010, No. 9, pp. 49-54. (In Russ.)

34. Yudin N.S., Ajtnazarov R.B., Knyazev S.P., Bekenev V.A., Deeva V.S., Goncharenko G.M., Kobzev V.F., Savina M.A., Ermolaev V.I., Nikitin S.V., Informacionnyj vestnik VOGIS, 2009, vol. 13, No. 4, pp. 741-750. (In Russ.)

35. Nikitin S.V., Knyazev S.P., Orlova G.V., Bekenev V.A., Danil"chenko N.V., Genetika, 2005, vol. 41, No. 2, pp. 237-245. (In Russ.)

36. Bogoljubskij S.N. Proishozhdenie i preobrazovanie domashnih zhivotnyh (The origin and transformation of pets), Moscow: Sov. nauka, 1959, 592 p.

37. Knyazev S.P., Nikitin S.V., Sel'skohozjajstvennaja biologija, 2014, No. 6, pp. 86-95. (In Russ.)

38. Nikitin S.V., Knyazev S.P., Ermolaev V.I., Genetika, 2014, vol. 50, No. 1, pp. 69-78. (In Russ.)

39. Knyazev S.P., Nikitin S.V., Ermolaev V.I., Vestnik NGAU, 2013, No. 1, pp. 46-57. (In Russ.)

40. Nikitin S.V., Knyazev S.P., Shatohin K.S., Vavilovskij zhurnal genetiki i selekcii, 2014, vol. 18, No. 2, pp. 279-293. (In Russ.)

41. Nikitin S.V., Knjazev S.P., Shatohin K.S., Zaporozhec V.I., Ermolaev V.I., Vavilovskij zhurnal genetiki i selekcii, 2018, vol. 22, No. 8, pp. 922-930. (In Russ.) 